\title{
Tremor after head injury and its treatment by stereotaxic surgery
}

\author{
J ANDREW, CJ FOWLER, MJG HARRISON
}

From the Departments of Neurosurgery and of Neurological Studies, the Middlesex Hospital and Medical School, London, UK

SUMMARY Tremor, both postural and kinetic may be a late complication for victims of severe closed head injury, especially in the young, and may add to their disability. The nature of the tremor is described in eight patients. In each a stereotaxic thalamotomy was performed, dramatically relieving or reducing the severity of tremor in each instance, and resulting in improved function of the affected limb and increased independence. The site of the responsible lesion, which is thought to lie in the mid brain, is discussed together with the indications and contraindications for surgical management.

In 1947, Kremer, Ritchie Russell, and Smythe ${ }^{1}$ described nine patients who had evidence of a midbrain syndrome following head injury. All of the patients were examined shortly after their injury in the Oxford Head Injury Centre. They showed a picture of dysarthria, occulomotor abnormalities and ataxia. In addition three showed a coarse postural tremor similar to that attributed by Holmes ${ }^{2}$ on clinical grounds, to a lesion of the red nucleus or superior cerebellar peduncle. The tremor after head injury can be both persistent and disabling. In this paper we review eight operated cases, to define further the clinical picture and to describe the response to thalamotomy.

\section{Methods}

All the patients referred with tremor or a related involuntary movement disorder after closed head injury were reviewed for details of their neurological presentation, clinical findings, investigations and operative details and follow up. They were all assessed as in-patients and had EEGs, air encephalography or more recently CT scans if stereotaxic surgery was considered. The EEGs and CT scans were reviewed for this report. Thalamotomy was carried out in all of the patients in two or more stages. Our procedure is as follows; under general anaesthesia, a multiperforated sphere is fixed into the vault of the skull, near the coronal suture, and held between two metal cups. Posi-

Address for reprint requests: $M r \mathrm{~J}$ Andrew, The Middlesex Hospital, Mortimer St, London W1N 8AA, UK.

Received 7 April 1982

Accepted 24 April 1982 tive contrast is injected into the ventricular system and using a stereotaxic frame the sphere is fixed so that a large area of the ventral part of the thalamus can be reached. Check radiographs are taken. A few days later when the patient has fully recovered, the thalamotomy is performed under local anaesthetic.

We believe the ideal target is the nucleus ventralis intermedius (Vim) extending into nucleus oralis externus (Oe). In the American terminology, Vim is referred to as VL (ventrolateral) nucleus and Oe as VA (ventralis anterior), although the lines of demarcation between these structures are not agreed. The ascending afferent pathways to Vim and the posterior part of the Oe come from the opposite dentate nucleus of the cerebellum and from the vestibular system as well as from muscle spindle receptors. The posterior boundary of Vim lies immediately anterior to Vce (ventralis caudalis externus), the somatosensory relay nucleus for the limbs and trunk, which is in the same coronal plane as the anterior limit of Vci (ventralis caudalis internus), which is the sensory relay nucleus for the face. This nucleus is readily indentified in macroscopic sections as a darkly stained semilunar structure. The anterior boundary of Vci lies between 11-16 mm posterior to IVF (interventricular foramen). ${ }^{3}$

Because of the inconstant distances between the reference points and nuclear boundaries, cell recording and electrical stimulation are required to define the target zone. A bipolar recording electrode of the type described by Albe-Fessard is used to record spontaneous activity as well as evoked responses. As the electrode is passed infero-posteriorly, spontaneous tremor rhythm firing may be encountered in the central region of the Vim. This zone has been called the "tremor pacemaker". As the electrode enters Vce, evoked muscle stretch responses may be obtained from the opposite limbs. It is undesirable to make a lesion more posteriorly in the Vci or Vce in the area where tactile responses are obtained, as this can be fol- 
lowed by persistent troublesome paraesthesiae at the corner of the mouth and in the thumb and index finger. When no evoked responses are obtained, reliance is placed on electrical stimulation to localise the electrode tip. Using a monopolar electrode with the remote electrode on the scalp an alternating current, with a stimulating voltage of $0 \cdot 5-2$ volts at $50-100 \mathrm{~Hz}$ is then applied. This may increase or decrease the tremor, and in either case a lesion at that site is usually successful. If a small current, given by a voltage of less than 1 volt causes paraesthesiae on the opposite side of the body, the electrode tip is probably too posterior in the sensory relay nuclei (that is Vce or Vci). A similar small current causing a myoclonic jerk would indicate too close proximity to the internal capsule.

The lesion is $6 \mathrm{~mm}$ long and has the shape of an oblate spheroid with a maximum diameter of $3-4 \mathrm{~mm} .{ }^{5}$ It is made by raising the temperature at the electrode tip to $66^{\circ} \mathrm{C}$ for 150 seconds using a radiofrequency current. The tremor is usually not completely abolished with a single lesion, so a second or even third lesion may be made on the same or on a subsequent occasion. The lesion may be extended anteriorly into Oralis externus (Oe), to interrupt the pallidofugal connections. The multiperforated sphere allows these subsequent lesions to be made if necessary.

\section{Results}

\section{CLINICAL FEATURES}

The eight patients ( 5 male: 3 female) were from 4 to 22 years old (mean 14.1) at the time of their head injury. The duration of coma ranged from 1 to 3 weeks except in one instance when it lasted for 5 months. In five hemiplegia had been present after the injury lasting from 2 to 18 months. In two patients there was a pseudobulbar palsy. Five showed pupillary or oculomotor signs suggesting a 3rd nerve palsy or upper midbrain damage at the time of the injury (table 1). Tremor developed after an interval of 1 to 18 months from the time of the head injury. It developed on the side of the hemiplegia as the hemiparesis receded in four and worsened as the paralysis recovered in the fifth. The movements were unilateral in all but 1 case and coincided with the side of the preceding hemiplegia in all but one instance. In the remaining three cases there had been pyramidal disturbance of a mild degree on the side of the tremor. Spontaneous improvement only appeared to have occurred in one patient. This was the case with tremor in both arms and as tremor improved on one side, it worsened on the other. One other patient described deterioration. Thus six showed no tendency to change over 1.5 to 14 years (mean 5.6 years). Seven of the patients had noted that voluntary movement aggravated the shaking of the tremulous limb. One patient felt that alcohol improved his tremor, and propranalol had produced some amelioration in another. Two had received tetrabennazine without benefit and another obtained no relief from haloperidol. The tremor was sufficiently severe to interfere with the use of the limb in all cases, and in five patients it made the limb useless. It was even sufficient to interfere with the use of the unaffected arm in one patient. The arm was always involved; the leg and face were only once seen to be involved.

The tremor was present at rest in three, and in all eight cases also occurred during the course of movements of the upper limb (kinetic tremor). In seven patients tremor was also seen on the maintenance of an outstretched posture (postural tremor). The actual posture affected the tremor in some cases. For example, in one man tremor was increased when $\cong$ the arm was held outstretched in a horizontal posi- $\triangle$ tion but abolished if he held his arms above his head. In one patient the postural tremor exceeded kinetic tremor, as occurs with essential tremor. In four cases tremor on movement exceeded that on maintenance of a posture and the picture was more like that seen in multiple sclerosis. In the other individuals postural and kinetic tremor was of equal severity. The only feature which appeared to distinguish this post traumatic tremor from that seen in conditions like multiple sclerosis and essential tremor was the superimposition in most (six cases) of jerks of a myoclonic nature. For example, these had been sufficiently striking in one case for the referring neurologist to have investigated the patient for other possible causes of myoclonus. In one of these cases the wild flinging movements of the arm were like hemiballismus and the patient would sit on her hand

Table 1

\begin{tabular}{|c|c|c|c|c|c|c|c|c|c|c|}
\hline Case & $\begin{array}{l}\text { Age: } \\
\text { Years }\end{array}$ & $M / F$ & $\begin{array}{l}\text { Coma: } \\
\text { Weeks }\end{array}$ & $\begin{array}{l}\text { Interval } \\
\text { HI to OP } \\
\text { Years }\end{array}$ & Dysarthria & $\begin{array}{l}\text { Eye } \\
\text { Signs }\end{array}$ & Ataxia & $\begin{array}{l}\text { Pyramidal } \\
\text { Signs }\end{array}$ & $\begin{array}{l}\text { EEG: } \\
\text { abnormal }\end{array}$ & $\begin{array}{l}C T: \\
\text { atrophy }\end{array}$ \\
\hline $\begin{array}{l}1 \\
2 \\
3 \\
4 \\
5 \\
6 \\
7 \\
8\end{array}$ & $\begin{array}{r}19 \\
29 \\
22 \\
6 \\
10 \\
20 \\
24 \\
13\end{array}$ & $\begin{array}{l}\mathbf{M} \\
\mathbf{M} \\
\mathbf{F} \\
\mathbf{F} \\
\mathbf{F} \\
\mathbf{M} \\
\mathbf{M} \\
\mathbf{M}\end{array}$ & $\begin{array}{r}20 \\
2 \\
3 \\
2 \\
1 \\
3 \\
2 \\
1\end{array}$ & $\begin{array}{l}2 \cdot 2 \\
9 \cdot 0 \\
14 \\
3 \cdot 6 \\
5 \cdot 9 \\
8 \cdot 25 \\
3 \cdot 8 \\
3 \cdot 3\end{array}$ & $\begin{array}{l}+ \\
- \\
+ \\
- \\
- \\
+ \\
+\end{array}$ & $\begin{array}{l}+ \\
- \\
+ \\
+ \\
+ \\
? \\
+ \\
-\end{array}$ & $\begin{array}{l}+ \\
- \\
+ \\
- \\
- \\
+ \\
+\end{array}$ & $\begin{array}{l}+ \\
+ \\
+ \\
+ \\
+ \\
+ \\
+ \\
+\end{array}$ & $\begin{array}{l}+ \\
+ \\
- \\
+ \\
? \\
+ \\
+ \\
+\end{array}$ & $\begin{array}{l}+ \\
? \\
+ \\
+ \\
+ \\
+ \\
+ \\
+\end{array}$ \\
\hline
\end{tabular}


with the elbow hyperextended. Sudden myoclonic jerks were also seen in the limb.

Four patients were dysarthric, the disturbance being attributed to a pseudobulbar palsy in one, but showing the characteristics of a cerebellar speech disorder in the other three. All the patients exhibited pyramidal signs (one tetraparetic; six hemiparetic; one bilateral extensor plantar responses), and four were unsteady on their feet. Two were unable to stand or walk unaided, due in one to the tetraparesis and in the other to ataxia. Only one showed residual evidence of a 3rd nerve palsy, but another had bilateral nystagmus.

Formal assessments of IQ were only made in two patients. Neither showed any evidence of a deterioration from premorbid levels that could be attributed to the head injury. Bedside assessments and accounts by parents and relatives similarly revealed no evidence of significant deterioration in intelligence in any of the other patients. One young man for example had been reading electronics at university when the accident occurred and showed no decline in intellectual level subsequently.

Each patient had an EEG; all but two of these showed diffuse non specific abnormalities compatible with the sequelae of head injury. None showed specific features that might be of localising value. Seven had CT scans all of which showed slight ventricular enlargement (unilateral in two, bilateral in five). In one instance there was evidence of an enlarged ambient cistern. One early case had had a normal lumbar air encephalogram.

\section{OPERATIVE DETAILS}

Evoked responses were sought in seven cases but only obtained in four. Spontaneous tremor rhythm firing was obtained in two cases. On one occasion stimulation decreased the tremor and on another it increased it. In both instances the electrode was thought to be close to the Vim-Vce boundary. In each case the first lesion was designed to be located mainly in the Vim, but just extending posteriorly into Vce. The posterior limit of the lesion lay between 18 and $14.7 \mathrm{~mm}$ behind the interventricular forearm (IVF) on the IVF-PC (posterior commissure) plane, its average distance behind the IVF being $16.0 \mathrm{~mm}$. The distance from the mid line was between 13-14 $\mathrm{mm}$ for the first lesion. In one patient tremor ceased after the first lesion. In two others, control of the tremor was obtained after making a second lesion. In five patients a third lesion was needed and this was made either anteriorly in Oe (Vop-Voa), more medially or above and parallel to the original lesion. In the seven patients in whom a second lesion was made, its posterior limit was either 3-4 mm anterior to the first, or more pos- teriorly if the first had been made more anteriorly than usual. When a third lesion was required this was made more anteriorly into the Oe-Vim, (two cases); $3 \mathrm{~mm}$ more medially at $10 \mathrm{~mm}$ from the mid line and $16 \mathrm{~mm}$ posterior to IVF (two cases). In another case the 3rd lesion was made above and parallel to the first lesion.

Immediately after operation the dysarthria and ataxia tended to be worse and in two cases the gait disturbance and dysarthria were severe for a number of weeks. Three had temporary deterioration in their hemiparesis. Three showed no adverse sequelae. The commonest picture was of a mild dysarthria and ataxia of the limbs with slight dragging of the contralateral foot reminiscent of the lacunar syndrome of ipsilateral ataxia and crural paresis described by Fisher and Cole in hypertensive subjects. ${ }^{6}$

The postural and kinetic tremor was greatly improved in seven cases and 50\% improved in the eighth. In two patients an initial improvement (approximately 50\%) was followed by a slowly progressive further improvement over several weeks. Rest tremor was always abolished, as was postural tremor, except in one case when occasional slight tremor was seen in the outstretched arm. Myoclonic jerks ceased in all cases. In seven patients some residual, though greatly reduced kinetic tremor was detectable as the target was reached during finger nose finger testing (table 2).

The functional improvement was striking. All were able to use the limb for feeding and personal hygiene, their ability to write improved (fig) and they were again able to drink from a cup, play "Scrabble", play the recorder etc.

\section{Discussion}

Holmes $^{2}$ argued from the findings of a geniculate field defect and ophthalmoplegia that a postural tremor in man was due to a lesion of the red nucleus ${ }^{7}$ or superior cerebellar peduncle. In the primate experimental lesions in the rubro-olivo-cerebellar

Table 2 Details of tremor before and after operation

\begin{tabular}{lllll}
\hline Case & \multicolumn{5}{l}{ Before/After operation } \\
\cline { 2 - 5 } & Rest & Postural & Kinetic & Jerking \\
\hline 1 & $+/-$ & $+/-$ & $+/+$ & $+/-$ \\
2 & $-/-$ & $+/-$ & $+/+$ & $+/-$ \\
3 & $+/-$ & $+/-$ & $+/+$ & $+/-$ \\
$\mathbf{4}$ & $-/-$ & $+/-$ & $+1+$ & $+/-$ \\
5 & $-/-$ & $-/-$ & $+/+$ & $+/-$ \\
6 & $-/-$ & $+/-$ & $+/-$ & $-/-$ \\
7 & $+/-$ & $+/-$ & $+/+$ & $-1-$ \\
$\mathbf{8}$ & $-/-$ & $+/-$ & $+/+$ & $+/-$ \\
$\mathbf{T}$ & $3 / 0$ & $7 / 0$ & $8 / 7$ & $6 / 0$ \\
\hline
\end{tabular}




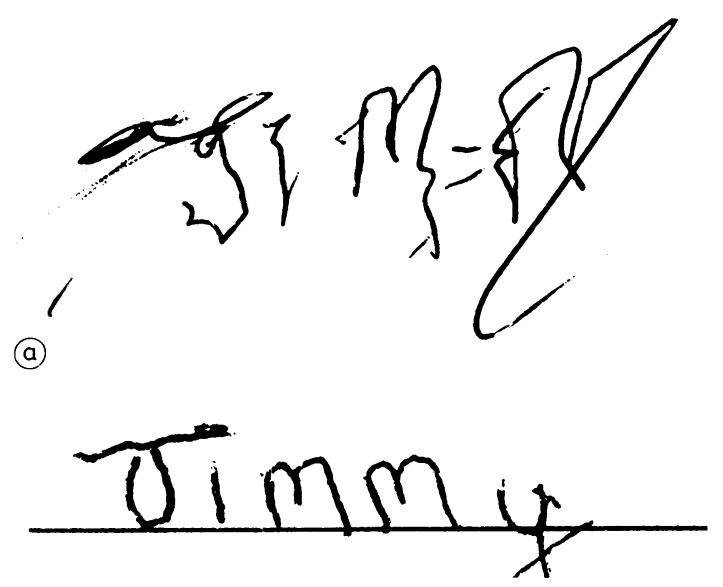

(b)

Figure Handwriting of patient 8 (a) before operation (b) after thalamotomy.

loop cause a similar postural tremor. ${ }^{8}$ The evidence from the present cases also supports a midbrain lesion as critical to the development of this type of tremor.

Primary brain stem damage in head injury commonly affects the superior cerebellar peduncles and their decussation. The region of the red nucleus, corticopontine and pontocerebellar fibres are frequently damaged. ${ }^{9} \mathrm{~A}$ recent series reporting results in necropsies on 35 cases of death from primary brain damage due to head injury showed 23 had discrete lesions in the midbrain which were not secondary to raised intracranial pressure or herniation at the tentorial opening but indicated that the midbrain is highly susceptible to damage in serious head injury. ${ }^{10}$ Our patients showed a combination of ataxia and pyramidal deficit in keeping with a midbrain lesion. Five patients in the present series showed evidence of an oculomotor lesion at the time of injury and in most cases the tremor was on the same side as a post traumatic hemiplegia, features in keeping with a lesion at the level of the superior cerebellar peduncle and its decussion. One patient showed evidence of midbrain atrophy on his CT scans. An identical tremor has been seen in a personally studied case with a midbrain arteriovenous malformation. That a kinetic and postural tremor of similar frequency may arise from lesions at other sites is however suggested by a further case in whom a small white matter infarct occurred just above the body of the opposite lateral ventricle. " $\mathrm{A}$ further unoperated patient had a haemorrhage in the caudate nucleus which could have been relevant to his tremor. ${ }^{12}$ Without necropsy data, it is, however, impossible to know whether these two patients also had midbrain lesions. More superficial cortical lesions may provoke tremor but in these rare cases the tremor is Parkinsonian in nature (Warlowe and Whitely, personal communication) being marked at rest and at a slightly faster frequency.

The head injury was in each case moderately severe with coma of at least a week's duration. A post-traumatic hemiplegia was common, tremor tending only to appear as the hemiplegia abated. The patients were all young, perhaps an indication of the very high mortality of such midbrain damage in older subjects.

The tremor, though showing some variability, had certain characteristics. It was present both on maintenance of a posture and on movement. In many cases jerky displacements occurred which were shock like and myoclonic in nature. These were commonly provoked by action as seen in post-anoxic action myoclonus. Flexion and extension movements of the digits were seen in two patients as described by Kremer et al. ${ }^{1}$ The patients were severely disabled by the tremor, unable to write, drink from a cup etc.

After placement of a stereotaxic lesion, all the patients had dramatic improvement in the usefulness of the arm thanks to loss of the postural tremor, loss of myoclonic jerking, and great reduction of the kinetic tremor. The surgical lesion tended temporarily to exaggarate dysarthria, ataxia, and crural weakness. These features are recognised after stereotaxic thalamotomy and it seems possible that the neurological deficit is equivalent to that seen with lacunar infarction described by Fisher. ${ }^{6}$ In one of his necropsy cases of homolateral ataxia and crural paresis there were lacunes in the basis pontis and in the putamen. In head injury victims who already show cerebellar and pyramidal deficits, the risks of these sequelae to thalamotomy are probably increased.

It is of great interest that the site for an effective lesion for relief of post-traumatic tremor is the same as that for tremor in multiple sclerosis, essential tremor, or Parkinsonism. This point has also been made by others, who have reported successful stereotaxic treatment of a variety of involuntary movements, ${ }^{13}$ some of which have followed head injury. ${ }^{1415}$ The implication is of course that the thalamic nuclei in the successful target area are involved in the final common pathway of the rhythmic activity. ${ }^{16}$ Albe Fessard ${ }^{17}$ has suggested that lesions in many sites (substantia nigra, cerebellum, cortex) may all cause increased rhythmic activity in the thalamus.

The decision to offer a patient a thalamotomy is an individual one. Ataxia, dysarthria and a 
pseudobulbar palsy are relative contra-indications though a severely handicapped chairbound patient may still benefit from the increased independence gained by relief of tremor. Since there was a tendency for some cases of post traumatic tremor to lessen spontaneously, thalamotomy should not be considered until at least one year has elapsed. Many of the patients have had a hemiparesis and surgery has only been offered after recovery of sufficient power so that the arm will be useful after relief of tremor. Since the inability to use one arm (because of tremor) can impede a child's development so dramatically, thalamotomy should not be delayed too long in the young. The shortest period in this series was as long as thirty-six months, because of late referral. As more young people survive the effects of civilian head injury it is to be anticipated that more patients will be left with disabling tremor. The reliable success of stereotaxic thalamotomy makes it the treatment of choice for this problem.

We are grateful to colleagues who referred patients and in particular to Mr RD Illingworth.

\section{References}

${ }^{1}$ Kremer M, Ritchie Russell W, Smyth GE. A midbrain syndrome following head injury. J Neurol Neurosurg Psychiatry 1947;10:49-60.

${ }^{2}$ Holmes G. On certain tremors in organic cerebral lesions. Brain 1904;27:327-75.

${ }^{3}$ Andrew J, Watkins ES. Stereotaxic Atlas of Human Thalamus. Baltimore: Williams and Wilkins, 1969.

4 Jasper HH, Bertrand G. Thalamic Units involved in somatic sensation and voluntary and involuntary movements in man. In: Purpura DP, Yahr MD, eds. The Thalamus. Columbia University Press, 1966;365-84.

${ }^{5}$ Andrew J. Surgery for involuntary movements. $\mathrm{Br} \mathrm{J}$ Hosp Med 1981;26:522-8.
- Fisher CM, Cole M. Homolateral ataxia and crural paresis: A vascular syndrome. J Neurol Neurosurg Psychiatry 1965:28:48-55.

${ }^{7}$ Guillain G, Bertrand I, Guillain J. Etude anatomoclinique sur une lesion ancienne du noyau rouge. $\operatorname{Rev}$ Neurol 1938;69:233-47.

${ }^{8}$ Larochell L, Bedard P, Boucher R, Poirier LJ. The Rubro-Olivo-Cerebello-Rubral Loop and Postural Tremor in the Monkey. J Neurol Sci 1970;1I:53-64.

${ }^{9}$ Tomlinson BE. Brain stem lesions after head injury. $J$ Clin Pathol. 1970;23 suppl 4:154-65.

${ }^{10}$ Rosenblum WI, Greenberg RP, Seelig JM, Becker DP. Midbrain Lesions: Frequency and significant prognostic features in closed head injury. Neurosurgery 1981;9:613-20.

" Andrew J, Fowler CJ, Harrison MJG, Kendall BK. Post traumatic tremor due to vascular injury and its treatment by stereotaxic thalamotomy. J Neurol Neurosurg Psychiatry (in Press).

${ }^{12}$ Maki Y, Akimoto H, Enomoto T. Injuries of Basal Ganglia following Head Trauma in Children. Child's Brain 1980;7:113-23.

${ }^{13}$ Narabayashi H, Chida T, Kondo T. Analysis of Two Factors influencing involuntary movement: Psychological stress effect and motor effect. Advances in Neurology, 24:362-71. New York: Raven Press, 1979.

${ }^{14}$ Ohye Ch, Fukamachi A, Miyazaki M, Isobe I, Nakajima H, Shibazaki T. Physiologically controlled selective thalamotomy for the treatment of abnormal movement by Leksell's open system. Acta Neurochir (Wein) 1977;37:93-104.

${ }^{15}$ Ohye Ch. Physiologically controlled selective Vim thalamotomy for various types of tremor. In: Integrative control functions of the Brain. Vol. 2. 188-189. M Ito, ed. Tokyo: Kodansha, 1979.

${ }^{16}$ Ohye Ch. Anatomy and physiology of the thalamic nucleus ventralis intermedius. In: Integrative control functions of the Brain 152-162 Vol. 1. M Ito, ed. Tokyo, Kodansha 1978.

${ }^{17}$ Albe Fessard D. Upon the possible role of rhythmic activities observed in Parkinsonian patients thalamus. In: Nicholson JP, ed. Interdisciplinary Investigation of the Brain. London: Plenum Press, 1979;83-96. 